Article

\title{
Investigation of the Internal Structure of Fiber Reinforced Geopolymer Composite under Mechanical Impact: A Micro Computed Tomography $(\mu \mathrm{CT})$ Study
}

\author{
Sneha Samal ${ }^{1}$, Marcela Kolinova ${ }^{2}$, Hubert Rahier ${ }^{3}{ }^{\mathbb{D}}$, Giovanni Dal Poggetto ${ }^{4}$ \\ and Ignazio Blanco $5, *$ (D) \\ 1 Institute of Physics of Czech Academy of Sciences, Na Slovance 1999/2, 18221 Prague, Czech Republic; \\ samal@fzu.cz \\ 2 The Institute for Nanomaterials, Advanced Technology and Innovation, Technical University of Liberec, \\ Studentská 2, 46117 Liberec, Czech Republic; marcela.kolinova@tul.cz \\ 3 Department of Physical Chemistry and Polymer Science (FYSC), Vrije Universiteit Brussel, Pleinlaan 2, \\ 1050 Brussel, Belgium; hrahier@vub.be \\ 4 Ecoricerche srl, Via Principi Normanni 36, 81043 Capua Caserta, Italy; giogiodp@hotmail.it \\ 5 Department of Civil Engineering and Architecture and UdR-Catania Consorzio INSTM, University of \\ Catania, Viale Andrea Doria 6, 95125 Catania, Italy \\ * Correspondence: iblanco@unict.it; Tel.: +39-095-738-2819
}

Received: 10 December 2018; Accepted: 30 January 2019; Published: 2 February 2019

\begin{abstract}
The internal structure of fiber reinforced geopolymer composite was investigated by microfocus X-ray computed tomography $(\mu \mathrm{CT})$ under mechanical impact. $\mu \mathrm{CT}$ is a non-destructive, multi approach technique for assessing the internal structures of the impacted composites without compromising their integrity. The three dimensional (3D) representation was used to assess the impact damage of geopolymer composites reinforced with carbon, E-glass, and basalt fibers. The 3D representations of the damaged area with the visualization of the fiber rupture slices are presented in this article. The fiber pulls out, and rupture and matrix damage, which could clearly be observed, was studied on the impacted composites by examining slices of the damaged area from the center of the damage towards the edge of the composite. Quantitative analysis of the damaged area revealed that carbon fabric reinforced composites were much less affected by the impact than the E-glass and basalt reinforced composites. The penetration was clearly observed for the basalt based composites, confirming $\mu \mathrm{CT}$ as a useful technique for examining the different failure mechanisms for geopolymer composites. The durability of the carbon fiber reinforced composite showed better residual strength in comparison with the E-glass fiber one.
\end{abstract}

Keywords: polymer composites; geopolymer; fiber; mechanical impact; micro-computed tomography; $\mu \mathrm{CT}$

\section{Introduction}

Over the past 35 years, microcomputed tomography $(\mu \mathrm{CT})$ has proved to be an effective and standard tool for quantifying structure-function relationships, disease progression, and preclinical models, thus contributing to scientific and bioengineering advancements [1]. $\mu \mathrm{CT}$ is a non-destructive imaging technique for the production of high-resolution three-dimensional (3D) images composed of two-dimensional (2D) trans-axial projections, or "slices", of a target specimen. Its principle is based on the attenuation of X-rays passing through the object or sample being imaged. As an X-ray passes 
through the object, the intensity of the incident $X$-ray beam is diminished according to the Equation (1):

$$
\mathrm{I}_{\mathrm{x}}=\mathrm{I}_{0} \mathrm{e}^{-\mu \mathrm{x}}
$$

where $I_{0}$ is the intensity of the incident beam, $x$ is the distance from the source, $I_{x}$ is the intensity of the beam at distance $x$ from the source, and $\mu$ is the linear attenuation coefficient [2].

Micro-CT can be used to evaluate volume and /or area using scanning pre- and post-endodontic treatment. The application of X-ray computed tomography and the assessment of measurement uncertainty regarding elements manufactured with the fused deposition modeling (FDM) method using 3D printing were performed [3]. The main advantage of using $\mu \mathrm{CT}$ is represented by the non-destructive acquisition of a complete model of the internal and external structure of the object with a higher resolution in respect to other techniques such as ultrasound and magnetic resonance imaging. The $\mu \mathrm{CT}$ can be applied on any surface, geometry, color, or material up to a certain density and/or thickness penetrable with X-rays. Recently, $\mu \mathrm{CT}$ is becoming increasingly important among the non-destructive inspection techniques for applications where the 3D nature of the phenomena is important and where the evolution of critical features is of interest, either during manufacturing or under in-service conditions. In the field of composites, the heterogeneity and architecture of the materials often require 3D assessment, while understanding the nucleation and evolution of defects is the key point for their structural integrity [4]. $\mu \mathrm{CT}$ allows one to slice through anywhere inside the object and inspect and identify defects (such as delaminations, cracks, and voids). It also allows for accurate measurements of structural features, reconstruction of a surface model to compare with Computer-Aided Drafting (CAD) drawings, and much more.

Geopolymers are an emerging class of materials widely used for the manufacturing of special concretes, thus proposing itself as an alternative to the Portland cement $[5,6]$. Geopolymer is considered a green cement and an eco-friendly material with suitable durability and mechanical and thermal properties for construction industries [7,8]. However, despite all of these features, their poor tensile and bending strengths due to the brittle and ceramic-like nature [9] can easily lead to failure and limits their use in several applications. Fiber reinforced geopolymer composites are considered a good solution for improving the flexural strength and fracture toughness due to a shift from a brittle failure mode to a ductile one [10].

Polymers, due to their ability to provide economic and structural benefits, can be considered the materials characterizing the last century. Continuing in this direction and trying to improve mechanical, thermal, and durability properties of polymers by adding various reinforcements to them, material experts are defining the composites as reference materials for the twenty-first century [11]. Composite materials have shown their superior performance over metals in many applications, such as in aerospace, automotive, and where high mechanical strength combined with low weight are required in general. Composites consist of a combination of materials that are mixed together to achieve specific structural properties. Normally, the components can be physically identified, as they interface with one another. A matrix supports the fibers and bonds them together in the composite material. The matrix transfers any applied loads to the fibers and keeps them in their position, thus giving resistance to the composite and determining its maximum service temperature. The properties of the composite are generally superior to those of the individual materials from which it is obtained, but its behavior under impact has been an important concern in many advanced engineered structures and components [12].

The potential application of composites in both low and high technology applications offers many advantages but suffers from shortcomings such as their weak impact resistance. Understanding the behavior of composites during impact is thus a crucial point to be considered for the improvement of the material properties [13]. The material's behavior towards runaway debris or objects that fall on its top surface determine the durability of the material, considering the residual strength depends on the damaged area upon impact [14]. A composite material is made of fibers embedded in a matrix, which is generally laminated with fibers oriented in alternating directions to give the material strength and stiffness [15]. For the construction of building structures, woven fabrics are usually the choice to 
save weight, minimize resin void size, and maintain fiber orientation during the fabrication process. In general, impact events cause combinations of damages [16]. The resulting damage may include significant fiber failure, matrix cracking, delamination, and debonded elements. Damage caused by low-energy impact is more contained but may also include a combination of broken fibers, matrix cracks, and multiple delaminations. Thus, it is essential to study the fiber orientation and the overall damage in fiber at the composite after impact under mechanical load [17].

Based on this assumption, a study was carried out on fiber reinforced geopolymer composite under mechanical load. The inner view of the composite on the point of structural integrity was carried out by investigating the damage of the fiber composite by the micro computed tomography method after mechanical impact. Although theoretical predictions about fiber orientation and porosity are presented, their combination with an experimental approach using micro computed tomography are not thoroughly addressed [18].

In a previous work, impact tests were carried out with a drop weight method on the surface of the composite material, and the residual strength of the composite in correlation with damage areas was explained [19]. Composites have complex characteristics and the presence of defects or damage will decrease their strength, thus initiating their ultimate failure [20].

In this work, we studied geopolymer composites with various fiber reinforcements, namely carbon, E-glass, and basalt. One general outcome (and the outcome of the present study) is the need to perform a detailed observation of the sample inner surface quality without any destructive changes. The geometrical defects that develop due to impact inside the fabric reinforced composite may play a determining role in the strength and life of the composite. The internal defects include fiber pull out, misalignment of the fiber, cracks, and damage to the matrix. In this work, we addressed the detailed statistical characterization of geometrical defects in the impacted fabric reinforced composite with 3D images captured by $\mu \mathrm{CT}$ to visualize the interior structural details with high resolution on a scale of interest for damage evaluation of the composite [21,22]. The relationships between the damaged area/volume and impact energies were established, and the composite was characterized, not only investigating the volume of the damaged area, but also the internal damage area including the internal structure and fiber breakage on the various layers of the composite structure. $\mu \mathrm{CT}$ was used to investigate the damaged area, fiber breakage from the surface to internal layers of the composite, delamination, and rupture of the fibers. Overall sustainability and durability of the composite were predicted by the $\mu \mathrm{CT}$ technique depending on the internal 3D image determined.

\section{Experimental}

\subsection{Materials}

Geopolymer binder was prepared by mixing $49 \%$ alumina-silicate powder, $44.12 \%$ alkali activator containing $\mathrm{NaOH} / \mathrm{KOH}$, and $6.88 \%$ metakaolin powder. The combination was stirred for $10 \mathrm{~min}$ by a home-made mixer machine for a complete homogenous mixture.

Composite samples $\left(100 \times 100 \times 3 \mathrm{~mm}^{3}\right)$ were prepared by hand lay up technique with fabrics of carbon (Figure 1a), E-glass (Figure 1b), and basalt (Figure 1c) reinforcement in alumino-silicate geopolymer matrices with metakaolin binders using piles of fabrics in the $0-90^{\circ}$ direction [12].

The assembled fabric reinforced geopolymer composites were placed in a vacuum bag and cured under $0.003 \mathrm{MPa}$ at room temperature for $24 \mathrm{~h}$. The bag with the composite was then placed in a curing oven at $70{ }^{\circ} \mathrm{C}$ for $12 \mathrm{~h} \mathrm{[12].} \mathrm{To} \mathrm{maintain} \mathrm{a} \mathrm{thickness} \mathrm{of} 3 \mathrm{~mm}$, the fabrics were arranged in different layers, such as 7 layers of E-glass, 10 layers of carbon, and 15 layers of basalt fabric. The volume fraction of the fiber, the matrix, and the voids of the three laminates were calculated according to the formulas reported in Equations (2)-(4):

$$
V_{f}=\frac{n \rho_{w}}{t \rho_{f}} \cdot 100 \%
$$




$$
\begin{gathered}
V_{m}=\frac{1}{t \rho_{m}}\left[\frac{m_{c}}{L b}-n \rho_{w}\right] \cdot 100 \% \\
V_{v}=100-\left(V_{f}+V_{m}\right)
\end{gathered}
$$

where $V_{f}, V_{m}, V_{v}$ are the volume fractions of fibers, matrix, and voids in a sample, $n$ is the number of fiber layers in a composite sample, and $t, L$, and $b$ are the thickness, length, and width of a composite sample, respectively. The volume fractions of fiber, matrix, and voids of the three laminates are reported in Table 1.

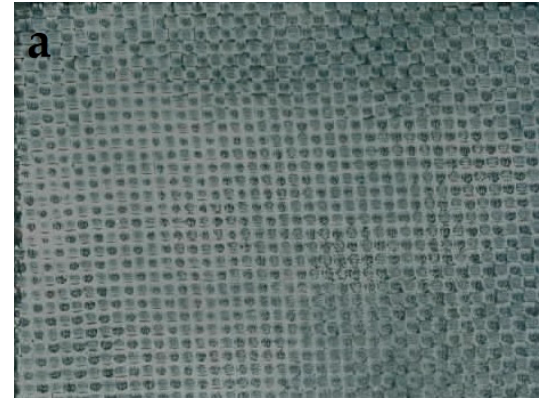

(a)

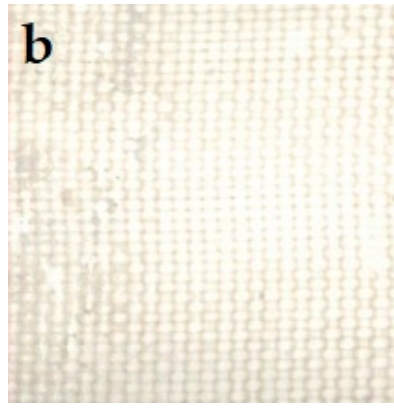

(b)

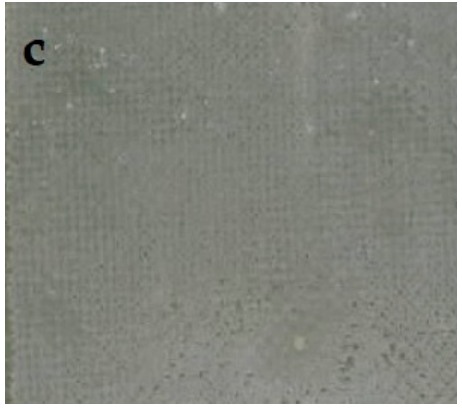

(c)

Figure 1. (a) Carbon fiber (b) E-glass fiber (c) Basalt fiber reinforced geopolymer composite before impact test.

Table 1. Density and volume fractions of fiber, matrix, and voids of the three reinforcements used.

\begin{tabular}{ccccc}
\hline Reinforcement & Density g/cm & Fiber V Fraction \% & Matrix V Fraction \% & Voids V Fraction \% \\
\hline Carbon & 1.51 & 39 & 40 & 21 \\
Basalt & 1.97 & 40 & 45 & 15 \\
E-glass & 1.80 & 41 & 37 & 22 \\
\hline
\end{tabular}

The geopolymer matrix composition was $2.04,31.80,0.08,15.15,1.74,0.63,0.24$, and $48.32 \%$ in $\mathrm{Al}$, $\mathrm{Si}, \mathrm{P}, \mathrm{K}, \mathrm{Zr}, \mathrm{Na}, \mathrm{Ca}$, and $\mathrm{O}$, respectively. The samples were impacted by the drop weight method, and the damage was created at the center of the material (Figure 2).

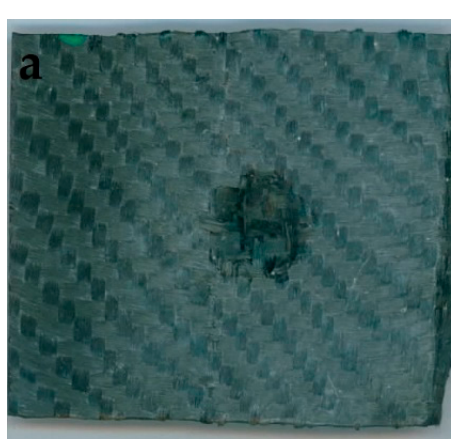

(a)

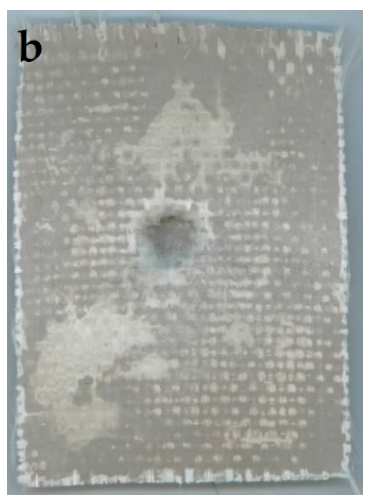

(b)

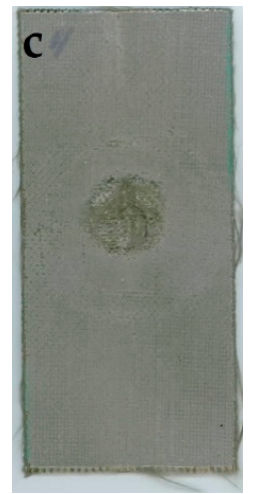

(c)

Figure 2. (a) Carbon (b) E-glass (c) Basalt fiber reinforced geopolymer composite after impact test.

The indenter was struck from the height of $0.50 \mathrm{~m}$ on the surface of the composite to create a notch. Five specimens for each material system with dimensions of $100 \times 130 \times 3 \mathrm{~mm}^{3}$ were tested with an in-house built drop weight factor. A hardened steel striker with a hemispherical tip of $16 \mathrm{~mm}$ diameter was impacted on the sample from a chosen drop height. The weight of the impactor was 
considered to be $3.072 \mathrm{~kg}$. The energy, $6.2 \mathrm{~J}$, was achieved from the chosen drop height of $0.50 \mathrm{~m}$. A schematic diagram of the system is reported in Figure 3.

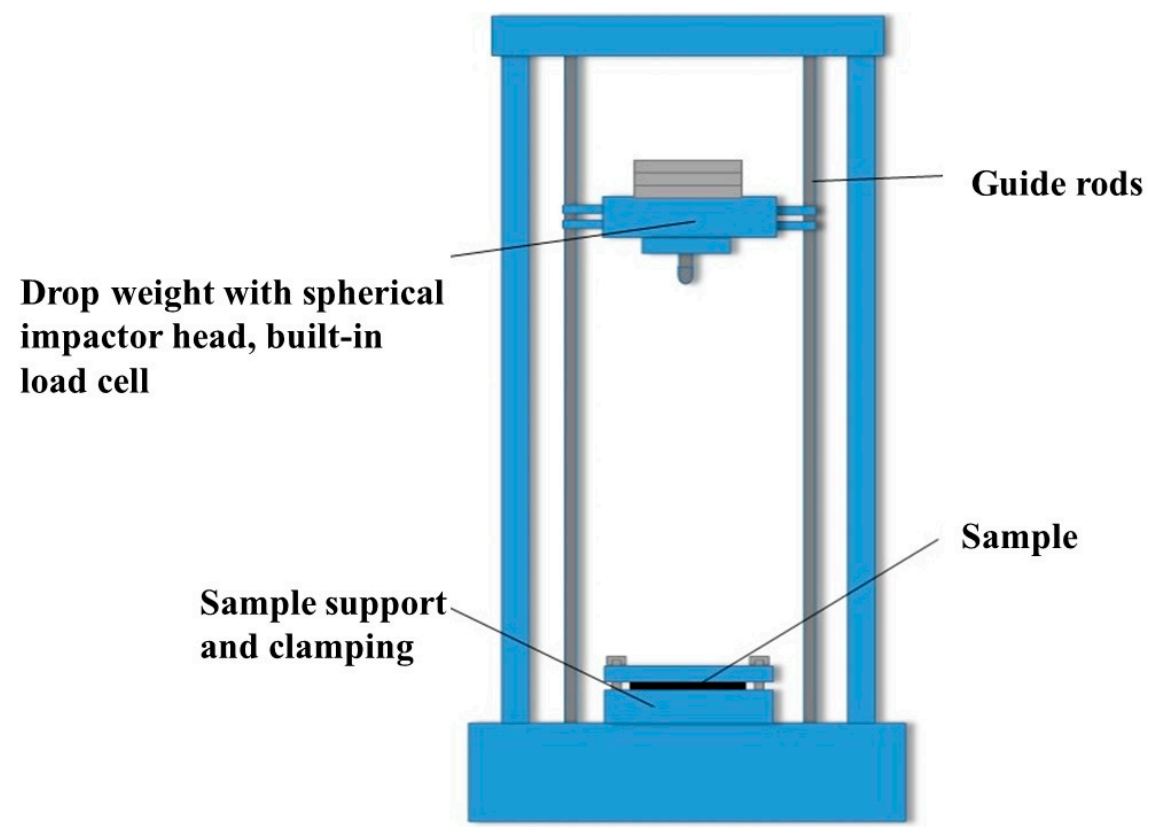

Figure 3. Schematic diagram of the system used for the impact tests.

The samples were examined in detailed damage areas using the $\mu \mathrm{CT}$ techniques before and after the impact test. The specimens for the $\mu \mathrm{CT}$ investigation were cut with a dimension of $50 \times 50$ $\times 3 \mathrm{~mm}^{3}$ around the central damage area. The distance of the outer edge was $25 \mathrm{~mm}$ towards the boundary from the center of impact and the notch generated on the composite surface.

\subsection{Micro Computed Tomography}

The $\mu \mathrm{CT}$ analysis was carried out in a SkyScan 1272 (Bruker, Kontich, Belgium) with a source voltage of $100 \mathrm{kV}$ and a source current of $100 \mu \mathrm{A}$ using a camera pixel size of $16 \mu \mathrm{m}$. Slices of the $\mu \mathrm{CT}$ images were collected from the impacted composite by scanning their images with the rotation of $0.28^{\circ}$. 3D images were built using the CT Vox graphics software (Bruker, Kontich, Belgium; parameters in Table 2). $\mu \mathrm{CT}$ imaging not only affords advantages over the conventional approach but also eliminates the tedious sample preparation.

Table 2. Microcomputed tomography $(\mu \mathrm{CT})$ scanning parameters for damage area evaluation (SkyScan 1272, Filter Cu $0.11 \mathrm{~mm})$.

\begin{tabular}{cccc}
\hline Source voltage & $100 \mathrm{kV}$ & Exposure & $2849 \mathrm{~ms}$ \\
Source current & $100 \mu \mathrm{V}$ & Rotation step & $0.4^{\circ}$ \\
Image pixel size & $16.0 \mu \mathrm{m}$ & Scanning position & $18 \mathrm{~mm}$ \\
Object to source & $193.3 \mathrm{~mm}$ & Reconstruction program & Nrecon \\
Camera to source & $268.6 \mathrm{~mm}$ & Ring artifact correction & 20 \\
Beam hardening correction & $0 \%$ & Scanning position & $18 \mathrm{~mm}$ \\
Cone beam angle horizontal & $15.16^{\circ}$ & Cone beam angle vertical & $5.17^{\circ}$ \\
No of projections & 2849 & X-ray spot target & $16 \mu \mathrm{m}$ \\
Total test time & $4 \mathrm{~h}$ & Camera Resolution & $1632 \times 1092$ \\
\hline
\end{tabular}

Besides analyzing internal structures of the composite, $\mu \mathrm{CT}$ provides a better understanding of the behavior and damage of the composite materials undergoing impact loading. The $\mu \mathrm{CT}$ method helps to detect and measure the fiber breakage, which leads to the basic understanding of the mechanisms of crack growth in composites. Three samples were tested for each individual specimen by the $\mu \mathrm{CT}$ 
method before and after damage. $\mu \mathrm{CT}$ slices were obtained and examined at each degree of composites rotation to observe differences in fiber rupture and matrix debonding. More than 450 slices were produced by $\mu \mathrm{CT}$ for each sample.

For the carbon fabric composite, a selection of the slices through the damaged area was done (Figure 4).
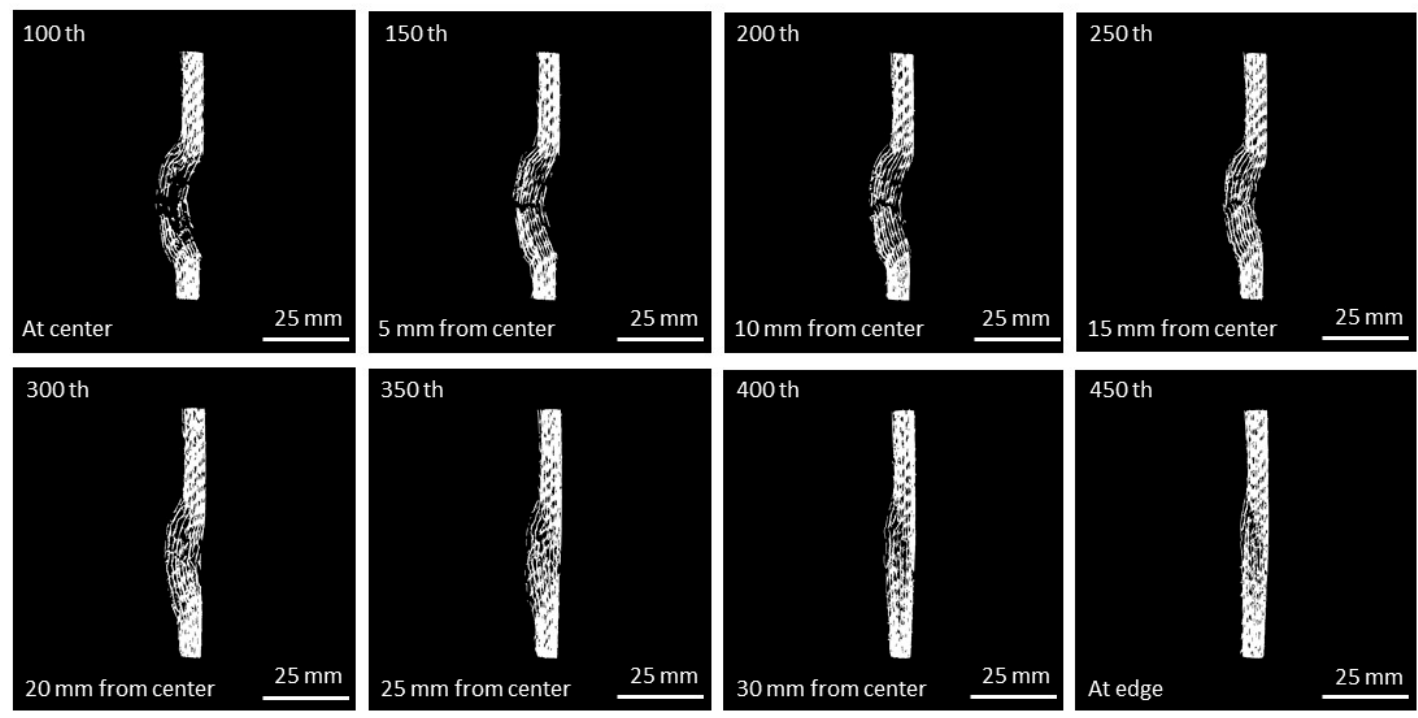

Figure 4. Carbon fiber composite after impact. $\mu \mathrm{CT}$ slices of damage from the center towards the edge. The fiber damage was investigated at the center and from each set of pictures, one picture was chosen at a distance of $5 \mathrm{~mm}$ towards the edge of the composite.

Using all of the slices, a 3D reconstruction image was created with the Vox software (Figure 5).

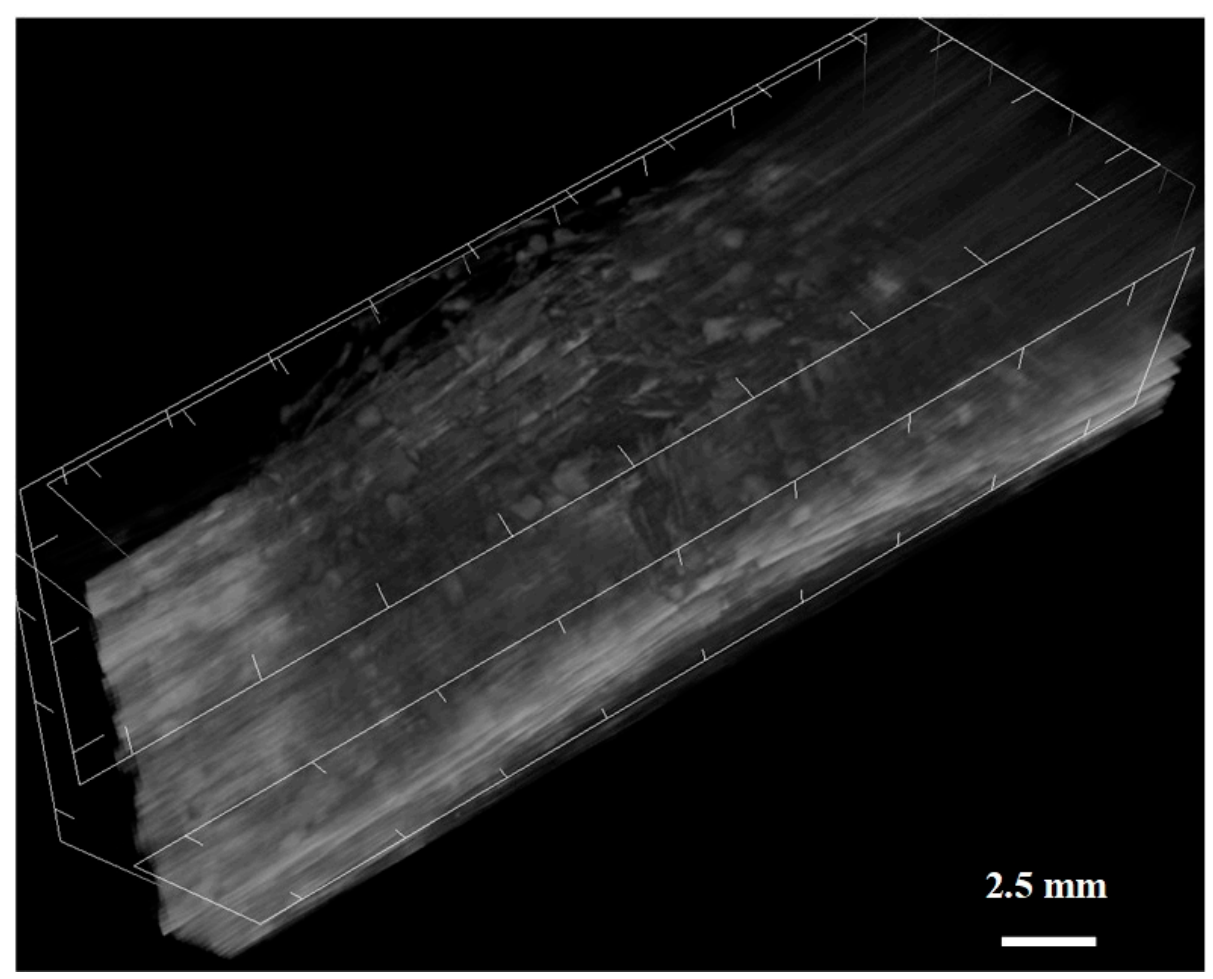

Figure 5. Three dimensional (3D) image after impact test of carbon fiber reinforced geopolymer composite. The part shows the area of impact. 


\section{Results and Discussion}

An area of $6.1 \times 6.5 \mathrm{~mm}^{2}$ was measured in carbon fabric reinforced composite (Figure 6a1-c1), showing a circular deformation on this composite surface. In longitudinal and transverse directions, broken fiber bundles in carbon fabric reinforced geopolymer composite were seen (Figure 6a2-c2), and the gap between the fibers became larger near the back side of the impact.
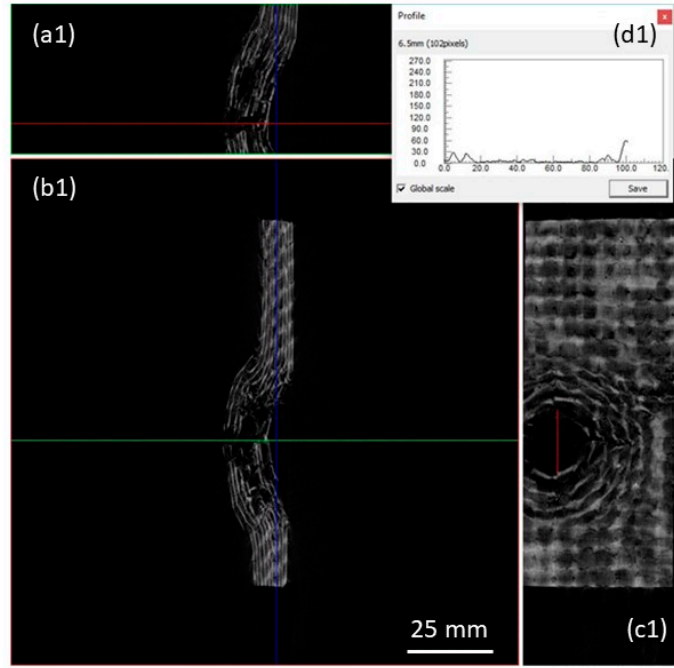
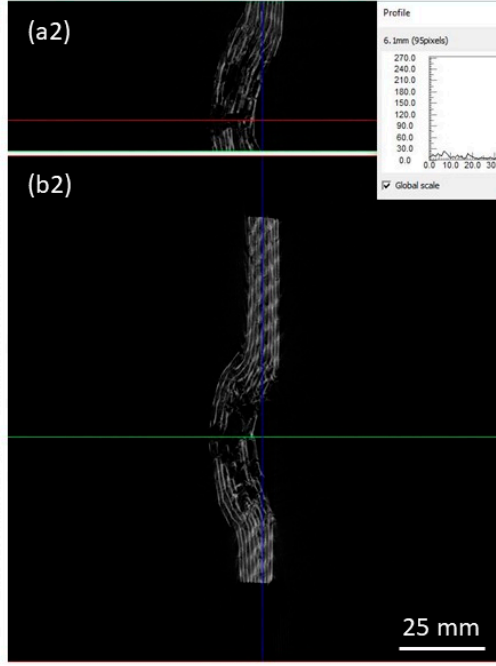
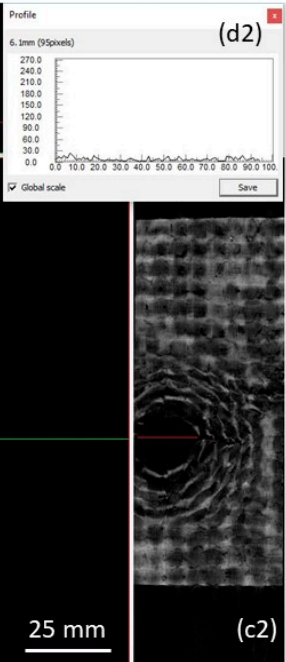

Figure 6. Slices and top view of the carbon fabric reinforced geopolymer composite after impact, a slice of (a1-c1) longitudinal and ( $\mathbf{a} 2-\mathbf{c} 2)$ transverse direction of the damaged area. The lines indicate where the other cross sections were taken. (d1-d2) Shows the response from the damaged area.

The depth of the hole was about half the thickness of the specimen and seemed to be thicker at the center of the impact.

For E-glass reinforced composites (Figures 7 and 8), the notch formation in the central region was much more pronounced than in the carbon fibers. Comparing Figures 4 and 7, it is clear that the damage stretched over a much wider area.
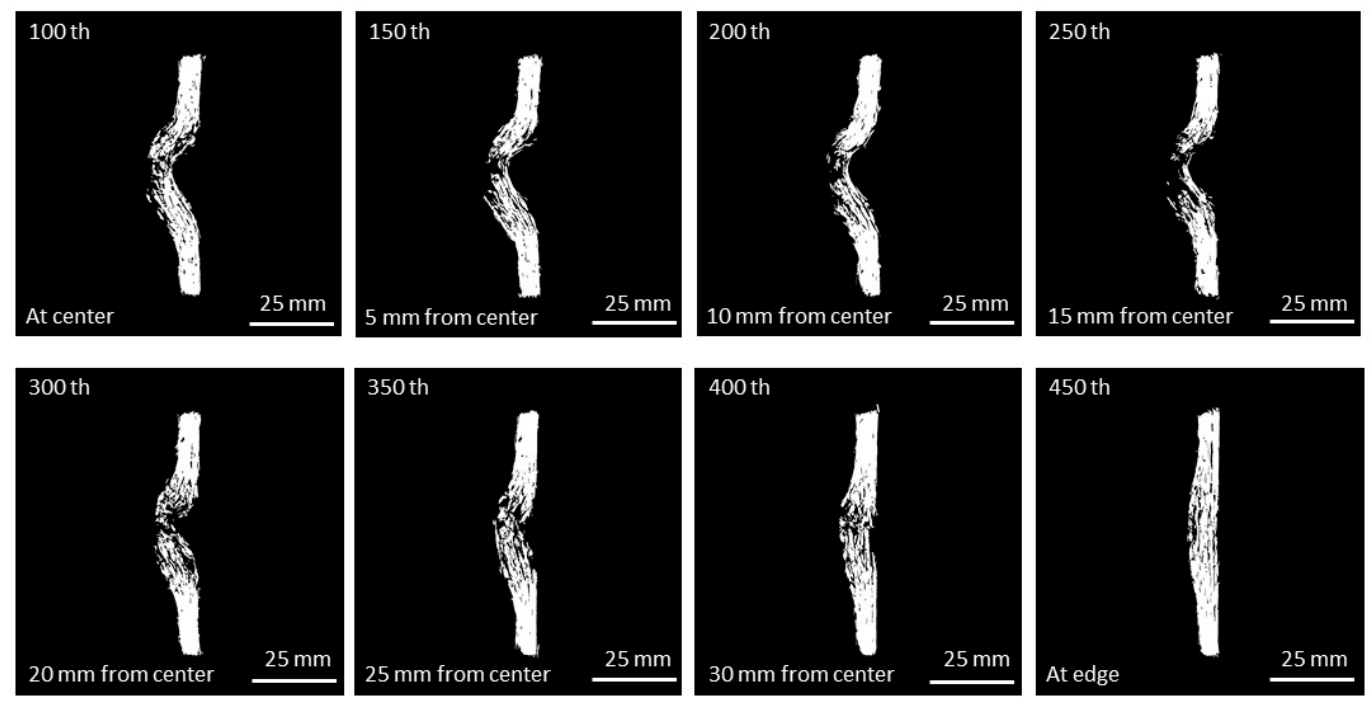

Figure 7. E-glass fiber composite after impact. $\mu \mathrm{CT}$ slices of damage from the center towards the edge. The fiber damage was investigated at the center and from each set of pictures, one picture was chosen at a distance of $5 \mathrm{~mm}$ towards the edge of the composite. 


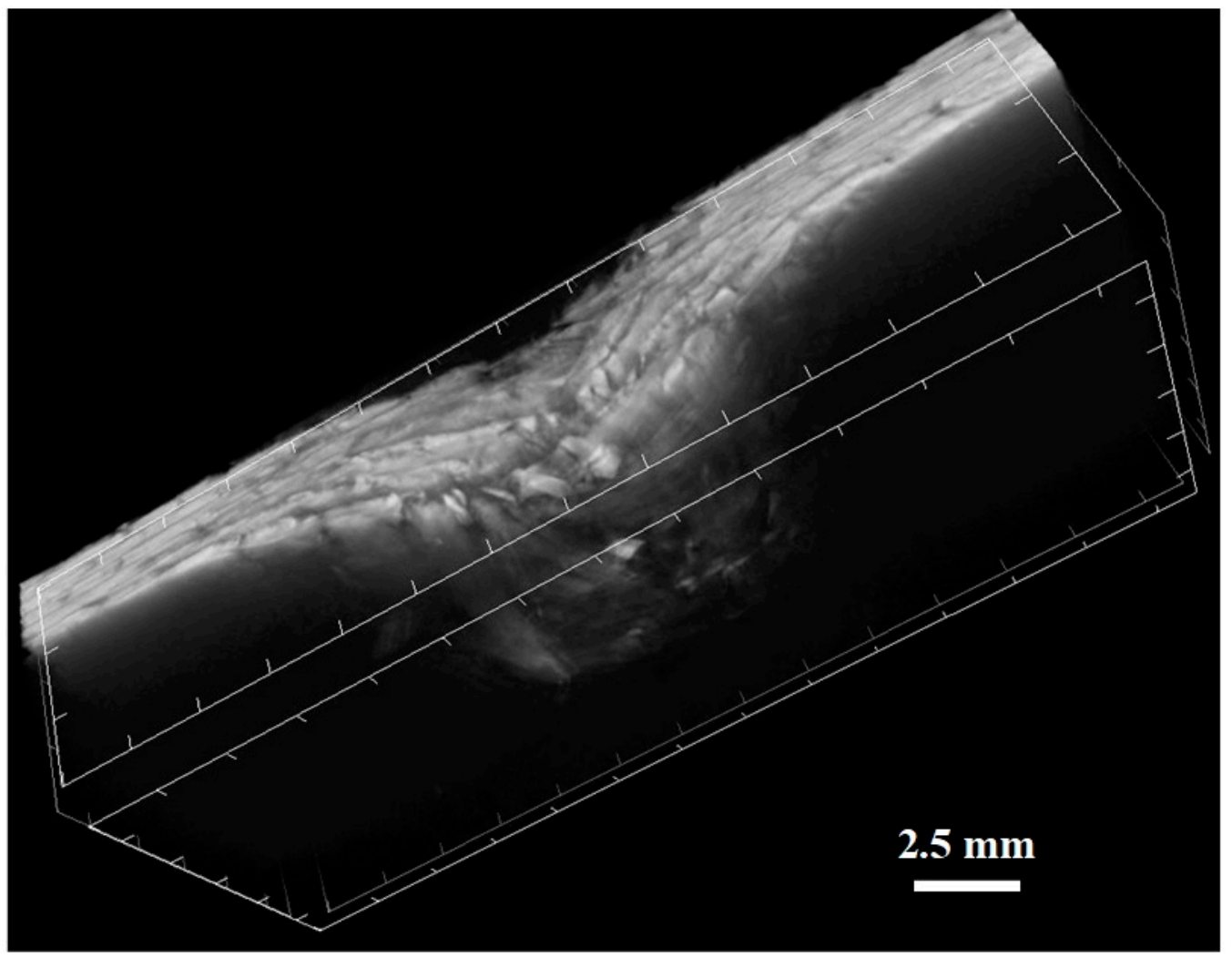

Figure 8. 3D image after impact test of E-glass fiber reinforced geopolymer composite. The part shows the area of impact.

Even in the top layer, the fiber rupture was more pronounced, which was evident from the slices in a longitudinal and transverse directions (Figure 9a1-c1,a2-c2).

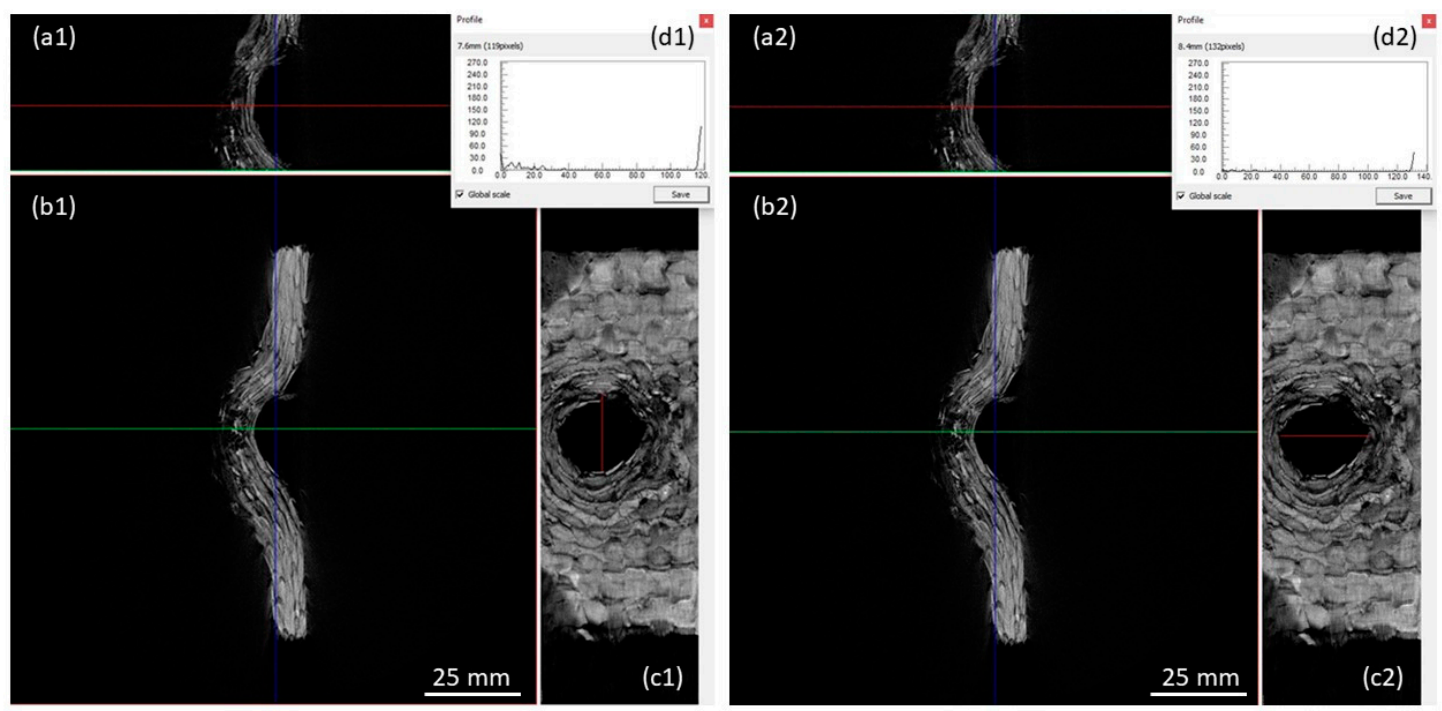

Figure 9. Slices and top view of the E-glass fabric reinforced geopolymer composite after impact test in longitudinal (a1-c1) and transverse (a2-c2) directions (the lines indicate where the other cross sections were taken). (d1-d2) The response from the damaged area. 
Fiber sliding was observed in the composite due to the slippery behavior of E-glass fabrics and the weak bonding between the fiber and the matrix of the composite. Fiber delamination on the various layers was observed in the composite in the area range of $50 \mathrm{~mm}$ towards its longitudinal direction. The slipping behavior of fibers within the matrix of the composite, as well as the loosening of the matrix within the damage zone, was very prominent. The depth of the hole was about twice the thickness of the sample. On the backside, fiber bundles were broken. Thus, the number of layers decreased when one approached the center of impact. This explains why the composite seemed to be thinner in the region of the impact.

The impact on the basalt geopolymer composite (Figure 10) was penetrated through its surface. There was extensive damage in the central area that spread out until the edge (Figure 10, slice 450). The specimen was completely deformed, and even the regions outside the impact zone remained permanently twisted due to the impact, as is clearly shown from the top images in Figure 10 where the two "flat" parts no longer lay in the same plane.
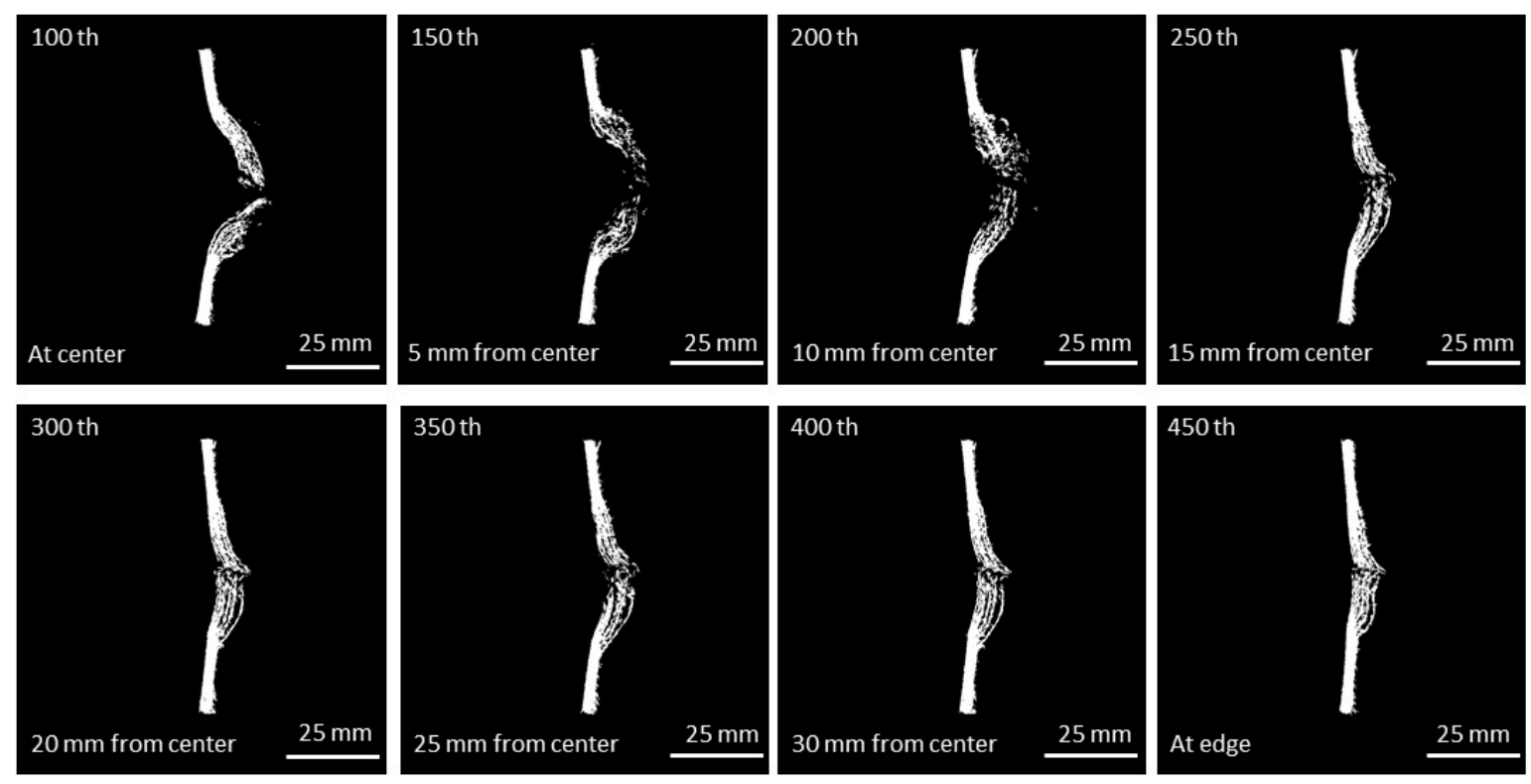

Figure 10. Basalt fiber composite after impact. $\mu \mathrm{CT}$ slices of damage from the center towards the edge. The fiber damage was investigated at the center and from each set of pictures, one picture was chosen at a distance of $5 \mathrm{~mm}$ towards the edge of the composite.

As a result, the remainder of the composite could only carry very negligible loads compared to the original value before the damage [23]. The overall image of the basalt fiber reinforced geopolymer composite is shown in Figure 11. The impact area was observed with a fiber rupture region from the top along the direction of the central impact rupture. 


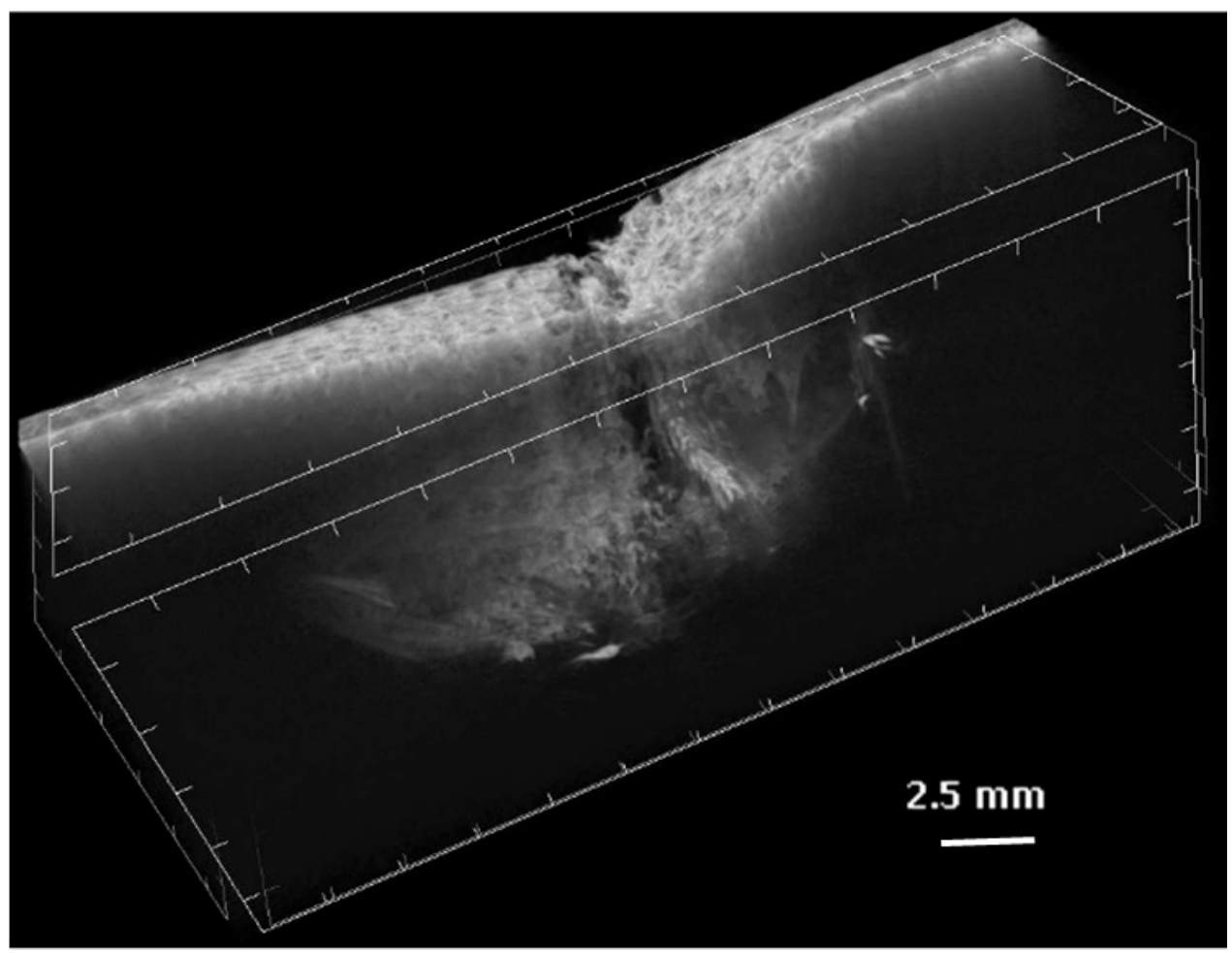

Figure 11. $\mu \mathrm{CT}$ analysis before and after the impact test of basalt fiber reinforced geopolymer composite. The part shows the area of impact.

The effect of the impact was very clear in the longitudinal and transverse directions (Figure 12a1-c1,a2-c2).
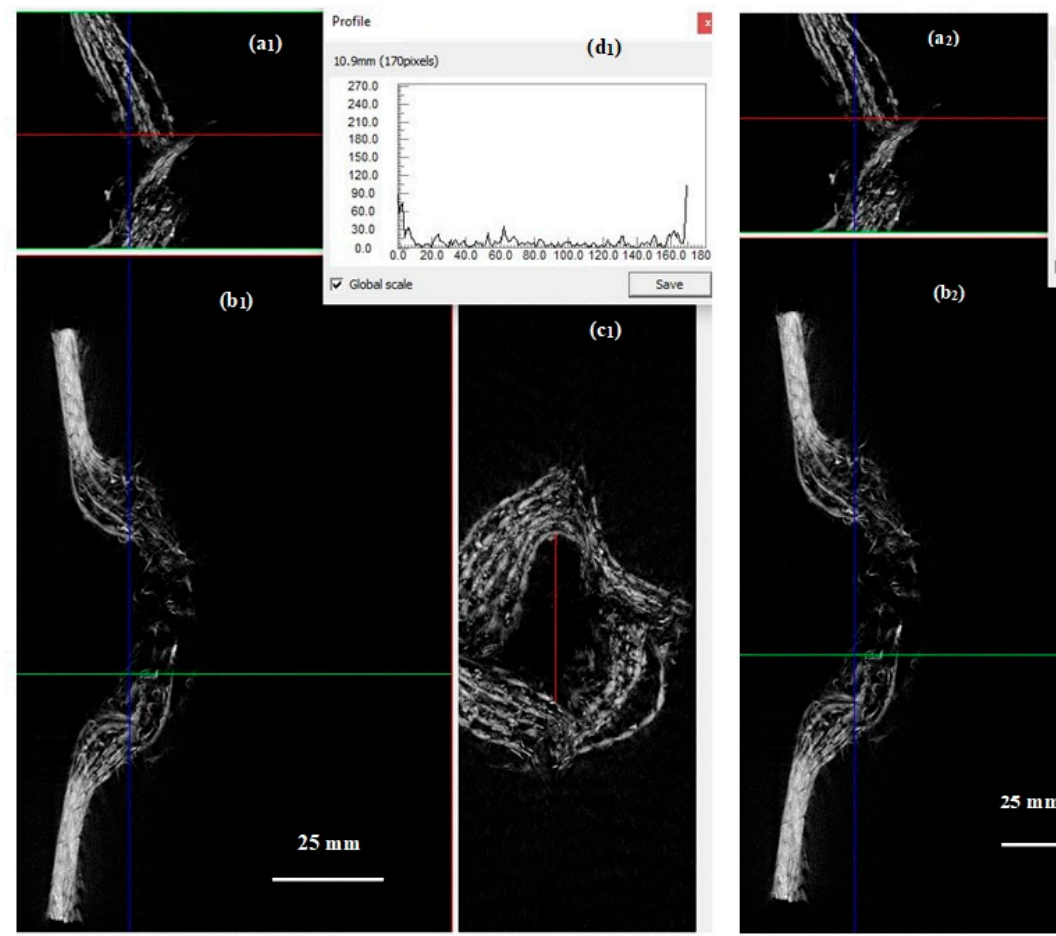

(b2)
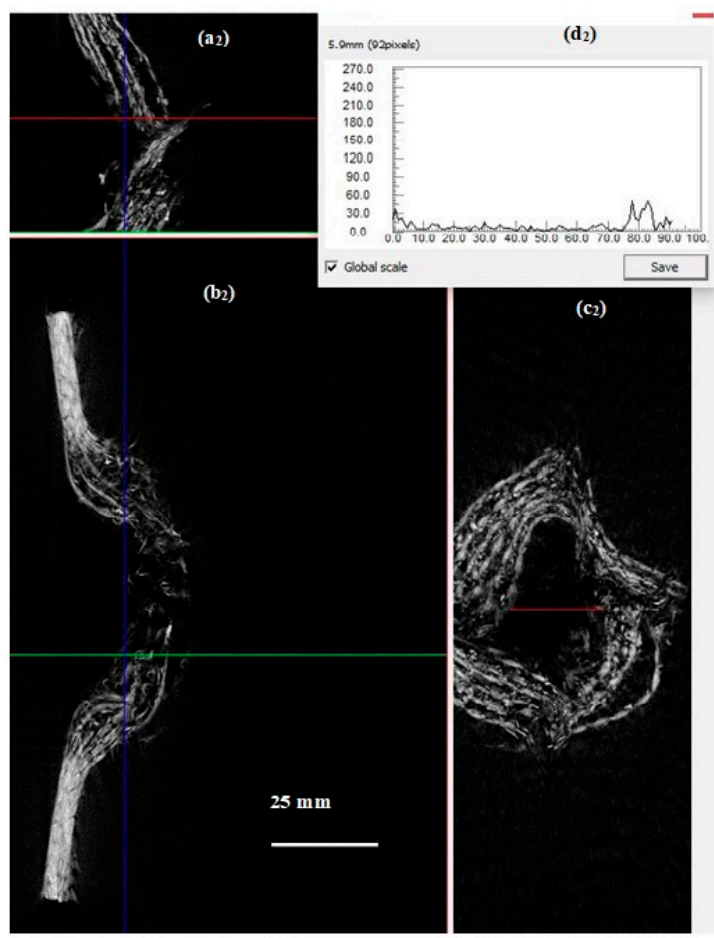

Figure 12. Slices and top view of the basalt fabric reinforced geopolymer composite after the impact test in longitudinal (a1-c1) and transverse (a2-c2) directions (the lines indicate where the other cross sections were taken). (d1-d2) The response from the damaged area. 
For the E-glass and the carbon fabrics, the delamination was visible, but the accompanying expansion in thickness was limited. The thickness of the basalt composite was more than double in the affected area. This behavior was attributed to the strong chemical interactions and the mineral exchange among the basalt fabrics and the geopolymer matrix [24]. Thus, strong chemical bonding transforms the composite-like cement structure, and above all, it weakens the fibers, showing the fragile behavior of the composite structure. The carbon fiber pull out around the impact zone was well explained by the concept of the laser scanner, and these observations match well with ours. The unidirectional carbon fibers in an epoxy matrix and the arrangement of the fibers in the laminar plane were studied using $\mu \mathrm{CT}$ [16], highlighting different failure modes of the composite and internal damage $[25,26]$ that agreed with the fiber damage concept presented in this study.

The central damage areas of the carbon, the E-glass, and the basalt fabric composites got larger in that order (Figure 13a-c). Fiber breakage and matrix cracks were observed in all cases [SEM micrographs of the damaged samples for E-glass (Figure S1) and basalt (Figure S2) fabric reinforced composites are reported as examples in the Supplementary Materials], however, for carbon composites, the area outside the range of $25 \mathrm{~mm}$ showed no change in appearance. The fiber damage within the central region was observed while the rest of the composite was intact with good adhesion of fibers within the matrix. The severely damaged area of the carbon geopolymer composite was $15 \pm 2 \mathrm{~mm}^{2}$ (calculated from the picture of the damaged area at the impact side), but the damage stretched over a larger circumferential area.
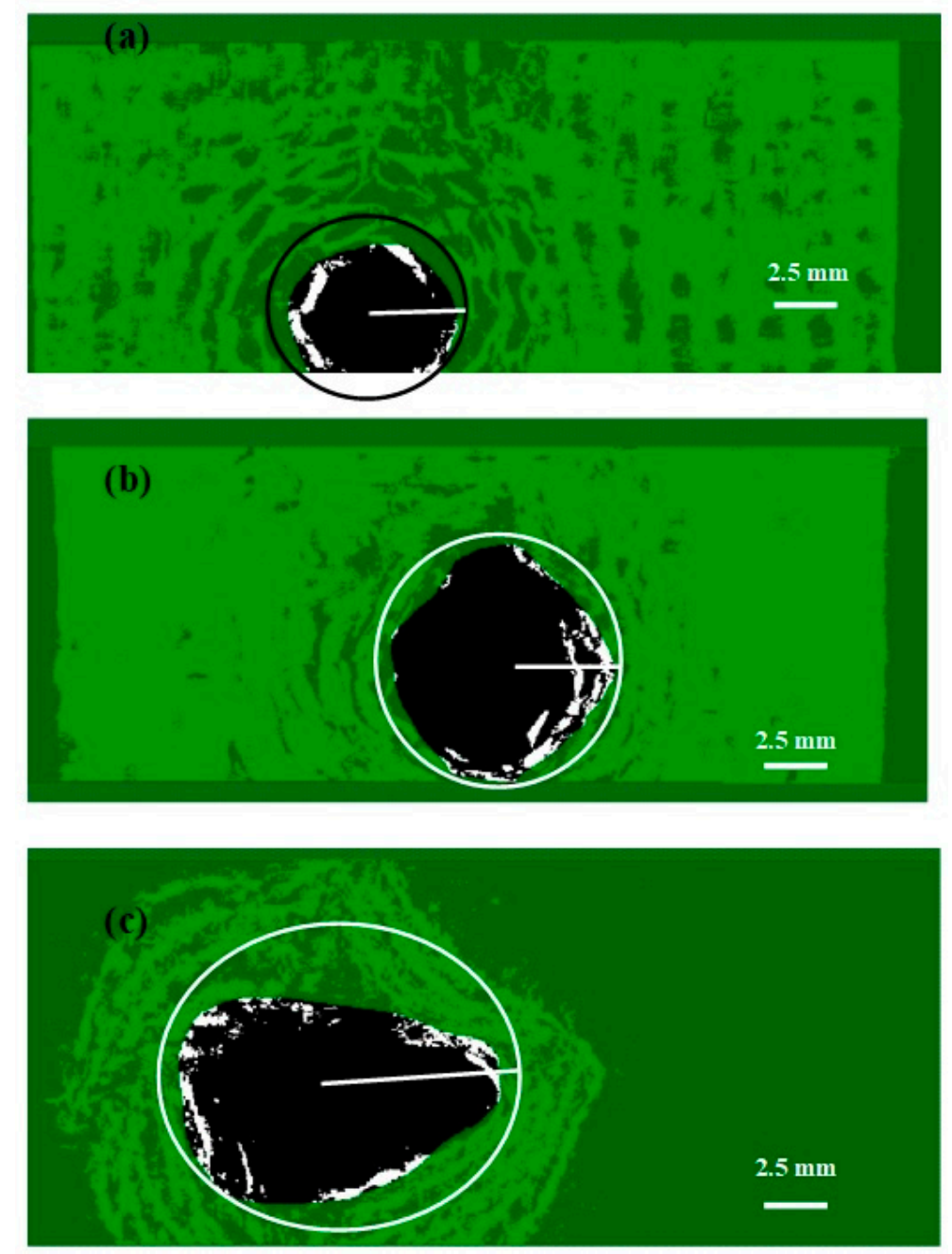

Figure 13. (a) The damage area of carbon, (b) E-glass, and (c) basalt reinforced composite. The green part represents the less affected area while the dark one represents the most affected area. 
This can be seen in Figure 5, where the affected zone was larger on the surface. The E-glass and the basalt composites showed only damage in the clearly distorted area with no effective changes in other parts of the composite. The pull out mechanism of the carbon fiber effectively impacted other parts of the composite, probably due to the inter shear stress mechanism [27]. The sliding mechanism of the E-glass fibers reduced the inter shear effect, while the basalt composite was penetrated suddenly, almost as if no fibers were present. The E-glass composites presented a severely damaged area in the range of $42 \pm 3 \mathrm{~mm}^{2}$. The basalt reinforced composite had a severely damaged area of $97 \pm 5 \mathrm{~mm}^{2}$. The area of damage is also represented in Figure 13, where the green part represents the non-affected area and the black one is the heavily distorted area. Not only was the affected area much larger for the basalt reinforced composites, but the shape of the impact was different as well. The non-spherical deformation was caused by the orientation of the textile fibers, which can also be seen in Figure 12c, where the deformation of the fiber bundles is very clear. The theoretical and experimental approach of woven fiber in the carbon composite at various axis of damage during dynamic loading was described in literature [28] and well matches with the damage behavior observed here, such as matrix cracking and fiber debonding on the composite. The overall fiber orientation and rupture through the composite from the edge towards the center is supported by the supplementary file Video S1.

The parameters for the 3D image construction and some results were compared to the carbon, the E-glass, and the basalt reinforced geopolymer composites (Table 3). The pixel size was fixed for all group images to $16 \mu \mathrm{m}$. The value of open porosity in the case of the carbon fabric reinforced composite showed $17 \%$, while the E-glass fabric showed $43 \%$, and the basalt composite showed the extreme value of $68 \%$ porosity.

Table 3. Parameters for the analysis of 3D images of impacted composites in the $\mu \mathrm{CT}$ techniques (pixel size: $16 \mu \mathrm{m})$.

\begin{tabular}{cccc}
\hline Experimental Parameters & Carbon Composite & E-glass Composite & Basalt Composite \\
\hline Number of Layers & 65 & 99 & 86 \\
Number of fibers & 174 & 520 & 423 \\
Number of closed pores & 0 & 0 & 5 \\
Volume of closed pores $\left(\mathrm{mm}^{3}\right)$ & 0.0 & 0.0 & 0.04 \\
Surface of closed pores $\left(\mathrm{mm}^{2}\right)$ & 0 & 0 & 1.96 \\
Closed porosity percentage $(\%)$ & 0.0 & 0.0 & 0.06 \\
Volume of open pore space $\left(\mathrm{mm}^{3}\right)$ & 99.61 & 242.37 & 559.99 \\
Total porosity $\%$ & 17.78 & 43.27 & 89.80 \\
\hline
\end{tabular}

The video shows the breakages of the fiber from the center to the edge and consists of more than 450 slices.

\section{Conclusions}

$\mu \mathrm{CT}$ reveals the internal geometry of the fabric reinforced composite materials, showing the overall image of the composite from the impact point towards the edge of the sample and the fiber breakage, notch, or depth of the impact areas. The advantages of this technique are that it not only shows the impact area but also very clearly shows the fiber rupture in the different slice images. Furthermore, other parameters-like porosity and sample position—can be obtained from the 3D image. The mechanism of damage of the composite is well explained on the basis of the $\mu \mathrm{CT}$ investigation of the damaged area. The following conclusions can be deduced from the obtained results:

1. Fabric reinforced composites were much less affected by the mechanical impact than the E-glass and the basalt reinforced composites.

2. As examined for basalt composites, $\mu \mathrm{CT}$ was found to be one of the most useful techniques for examining the different failure mechanisms for geopolymer composites. 
3. $\mu \mathrm{CT}$ provided the internal geometry (including $3 \mathrm{D}$ image) of the fabric reinforced composite materials, including parameters like porosity and sample position. This is the prime advantage of $\mu \mathrm{CT}$ over other techniques.

4. Our study showed that the durability of the carbon fiber reinforced composite showed better residual strength in comparison with the E-glass fiber one.

5. The carbon fiber reinforced composite had a much better impact resistance, with fiber damage only in the central area with a limited amount of fiber sliding in the surrounding areas.

Supplementary Materials: The following are available online at http:/ /www.mdpi.com/2076-3417/9/3/516/s1, Figure S1: SEM images of E-glass geocomposite after damage, showing matrix rupture, fibre pull out and non-adhesion. Figure S2. SEM images of Basalt reinforced geocomposite after impact test, showing the fiber breakage, matrix cracks, non-adhesion of fabric-matrix interface, Video S1: 3D analysis of basalt fiber from center to edge in basalt fiber reinforced composite

Author Contributions: S.S., M.K., H.R. and I.B. conceived and designed the experiments; S.S., M.K. and H.R. performed the experiments; S.S., M.K. and H.R. analyzed the data; S.S., M.K., H.R., G.D.P. and I.B. wrote the paper.

Funding: Ignazio Blanco is grateful to the MIUR for the grant "Fund for basic research activities", and to the Department of Civil Engineering and Architecture of the University of Catania for supporting the project MATErials LIfe foreCAst (MATELICA).

Conflicts of Interest: The authors declare no conflict of interest.

\section{References}

1. Boerckel, J.D.; Mason, D.E.; McDermott, A.M.; Alsberg, E. Microcomputed tomography: Approaches and applications in bioengineering. Stem. Cell. Res. Ther. 2014, 5, 144. [CrossRef] [PubMed]

2. Stauber, M.; Müller, R. Micro-computed tomography: A method for the non-destructive evaluation of the three-dimensional structure of biological specimens. Methods Mol. Biol. 2008, 455, 273-292. [CrossRef] [PubMed]

3. Gapiński, B.; Wieczorowski, M.; Grzelka, M.; Alonso, P.A.; Bermúdez Tomé, A. The application of micro computed tomography to assess quality of parts manufactured by means of rapid prototyping. Polimery 2017, 62, 53-59. [CrossRef]

4. Garcea, S.C.; Wang, Y.; Withers, P.J. X-ray computed tomography of polymer composites. Compos. Sci. Technol. 2018, 156, 305-319. [CrossRef]

5. Davidovits, J. Geopolymers. J. Therm. Anal. 1991, 37, 1633-1656. [CrossRef]

6. Palankar, N.; Ravi Shankar, A.U.; Mithun, B.M. Studies on eco-friendly concrete incorporating industrial waste as aggregates. Int. J. Sustain. Built Environ. 2015, 4, 378-390. [CrossRef]

7. Samal, S.; Thanh, N.P.; Petríková, I.; Marvalová, B. Improved mechanical properties of various fabric-reinforced geocomposite at elevated temperature. JOM 2015, 67, 1478-1485. [CrossRef]

8. Samal, S.; Thanh, N.P.; Marvalová, B.; Petríková, I. Thermal Characterization of Metakaolin-Based Geopolymer. JOM 2017, 69, 2480-2484. [CrossRef]

9. Natali, A.; Manzia, S.; Bignozzi, M.C. Novel fiber-reinforced composite materials based on sustainable geopolymer matrix. Procedia Eng. 2011, 21, 1124-1131. [CrossRef]

10. Nematollahi, B.; Ranade, R.; Sanjayan, J.; Ramakrishnan, S. Thermal and mechanical properties of sustainable lightweight strain hardening geopolymer composites. Arch. Civ. Mech. Eng. 2017, 17, 55-64. [CrossRef]

11. Blanco, I. The Rediscovery of POSS: A Molecule Rather than a Filler. Polymers 2018, 10, 904. [CrossRef]

12. Samal, S.; Reichmann, D.; Petríková, I.; Marvalová, B. Low Velocity Impact on Fiber Reinforced Geocomposites. Appl. Mech. Mat. 2016, 827, 145-148. [CrossRef]

13. Samal, S.; Marvalová, B.; Petríková, I.; Vallons, K.A.M.; Lomov, S.V.; Rahier, H. Impact and post impact behavior of fabric reinforced geopolymer composite. Constr. Build. Mater. 2016, 127, 111-124. [CrossRef]

14. Pelivanov, I.; Ambrozinski, L.; Khomenko, A.; Koricho, E.G.; Cloud, G.L.; Haq, M.; O’Donnell, M. High resolution imaging of impacted CFRP composites with a fiber-optic laser-ultrasound scanner. Photoacoustics 2016, 4, 55-64. [CrossRef] [PubMed]

15. Samal, S.; Thanh, N.P.; Petríková, I.; Marvalová, B.; Vallons, K.A.M.; Lomov, S.V. Correlation of microstructure and mechanical properties of various fabric reinforced geo-polymer composites after exposure to elevated temperature. Ceram. Int. 2015, 41, 12115-12129. [CrossRef] 
16. Pasupathy, K.; Berndt, M.; Castel, A.; Sanjayan, J.; Pathmanathan, R. Carbonation of a blended slag-fly ash geopolymer concrete in field conditions after 8 years. Constr. Build. Mater. 2016, 25, 661-669. [CrossRef]

17. Sisodia, S.M.; Garcea, S.C.; George, A.R.; Fullwood, D.T.; Spearing, S.M.; Gamstedt, E.K. High-resolution computed tomography in resin infused woven carbon fibre composites with voids. Compos. Sci. Technol. 2016, 131, 12-21. [CrossRef]

18. Tan, K.T.; Watanabe, N.; Iwahori, Y. X-ray radiography and micro-computed tomography examination of damage characteristics in stitched composites subjected to impact loading. Compos. Part B 2011, 42, 874-884. [CrossRef]

19. Ullah, H.; Harland, A.R.; Silberschmidt, V.V. Dynamic bending behaviour of woven composites for sports products: Experiments and damage analysis. Mater. Des. 2015, 88, 149-156. [CrossRef]

20. Wang, Y.; Burnett, T.L.; Chai, Y.; Soutis, C.; Hogg, P.J.; Withers, P.J. X-ray computed tomography study of kink bands in unidirectional composites. Compos. Struct. 2017, 160, 917-924. [CrossRef]

21. Samal, S.; Vlach, J.; Kolinova, M.; Kavan, P. Micro-Computed Tomography Characterization of Isotropic Filler Distribution in Magnetorheological Elastomeric Composites. In Advanced Processing and Manufacturing Technologies for Nanostructured and Multifunctional Materials; Ohji, T., Singh, M., Halbig, M., Moon, K., Eds.; Wiley: Hoboken, NJ, USA, 2017; Chapter 7; pp. 57-69. ISBN 9781119321705.

22. Samal, S.; Kolinova, M.; Blanco, I. The Magneto-Mechanical Behavior of Active Components in Iron-Elastomer Composite. J. Compos. Sci. 2018, 2, 54. [CrossRef]

23. Benfratello, S.; Fiore, V.; Palizzolo, L.; Scalici, T. Evaluation of continuous filament mat influence on the bending behaviour of GFRP pultruded material via Electronic Speckle Pattern Interferometry. Arch. Civ. Mech. Eng. 2017, 17, 169-177. [CrossRef]

24. Mayr, G.; Plank, B.; Sekelja, J.; Hendorfer, G. Active thermography as a quantitative method for non-destructive evaluation of porous carbon fiber reinforced polymers. NDT E Int. 2011, 44, 537-543. [CrossRef]

25. Awaja, F.; Nguyen, M.-T.; Zhang, S.; Arhatari, B. The investigation of inner structural damage of UV and heat degraded polymer composites using X-ray micro CT. Compos. Part A 2011, 42, 408-418. [CrossRef]

26. Crupi, V.; Epasto, G.; Guglielmino, E. Computed Tomography analysis of damage in composites subjected to impact loading. Frattura ed Integrità Strutturale 2011, 5, 32-41. [CrossRef]

27. Fidan, S.; Snmazçelik, T.; Avcu, E. Internal damage investigation of the impacted glass/glassaramid fiber reinforced composites by micro-computerized tomography. NDT E Int. 2012, 51, 1-7. [CrossRef]

28. Patel, D.K.; Waas, A.M. Damage and failure modelling of hybrid three-dimensional textile composites: A mesh objective multi-scale approach. Philos. Trans. A Math. Phys. Eng. Sci. 2016, 374, 20160036. [CrossRef] 